\title{
White Matter Alterations in Fmr1 Knockout Mice during Early Postnatal Brain Development
}

\author{
Da Shi ${ }^{a, b}$ Su Xu ${ }^{a}$ Jiachen Zhuo ${ }^{a}$ Mary C. McKennac, d Rao P. Gullapallia,b, d \\ a Department of Diagnostic Radiology and Nuclear Medicine, University of Maryland School of Medicine, \\ Baltimore, MD, USA; ${ }^{b}$ Department of Biochemistry and Molecular Biology, University of Maryland School of \\ Medicine, Baltimore, MD, USA; ${ }^{\circ}$ Department of Pediatrics, University of Maryland School of Medicine,

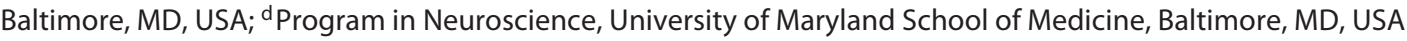

\section{Keywords}

Fragile $X$ syndrome $\cdot F m r 1$ knockout $\cdot$ Magnetization transfer $\cdot \mathrm{T}_{2}$ relaxation $\cdot$ Myelination

\begin{abstract}
Fragile $\mathrm{X}$ syndrome (FXS) is the most commonly inherited form of intellectual disability ascribed to the autism spectrum disorder. Studies with FXS patients have reported altered white matter volume compared to controls. The Fmr 1 knockout (KO) mouse, a model for FXS, showed evidence of delayed myelination during postnatal brain development. In this study, we examined several white matter regions in the male Fmr $1 \mathrm{KO}$ mouse brain compared to male wild-type (WT) mice at postnatal days (PND) 18, 21, 30, and 60, which coincide with critical stages of myelination and postnatal brain development. White matter volume, $\mathrm{T}_{2}$ relaxation time, and magnetization transfer ratio (MTR) were measured using magnetic resonance imaging and myelin content was determined with histological staining of myelin. Differences in the developmental accumulation of white matter and myelin between Fmr1 KO and WT mice were observed in the corpus callosum, external and internal capsules, cerebral peduncle, and fimbria. Alterations were more predominant in the external and internal capsules and fimbria of Fmr1 KO mice,
\end{abstract}

where the MTR was lower at PND 18, then elevated at PND 30, and again lower at PND 60 compared to the corresponding regions in WT mice. The pattern of changes in MTR were similar to those observed in myelin staining and could be related to the altered protein synthesis that is a hallmark of FXS. While no significant changes in white matter volumes and $\mathrm{T}_{2}$ relaxation time between the Fmr1 KO and WT mice were observed, the altered pattern of myelin staining and MTR, particularly in the external capsule, reflecting the abnormalities associated with myelin content is suggestive of a developmental delay in the white matter of Fmr $1 \mathrm{KO}$ mouse brain. These early differences in white matter during critical developmental stages may contribute to altered brain networks in the Fmr1 KO mice.

๑) 2020 S. Karger AG, Basel

\section{Introduction}

Fragile X syndrome (FXS) is the most commonly inherited form of sex-linked intellectual disability affecting 1 in 5,000 males [1]. FXS causes intellectual disability and behaviors commonly seen in the autism spectrum disorder, including hyperactivity, social anxiety, and attentional problems $[1,2]$. FXS is caused by the mutational

\section{KARGER}

(c) 2020 S. Karger AG, Basel

karger@karger.com

www.karger.com/dne
Prof. Rao P. Gullapalli, PhD

Department of Diagnostic Radiology and Nuclear Medicine University of Maryland School of Medicine

670 W Baltimore St, Rm L127, Baltimore, MD 21201 (USA)

rgullapalli@som.umaryland.edu 
insertion of CGG trinucleotide repeats, which leads to the epigenetic silencing of the FMR1 gene [3]. The silencing results in the loss of the mRNA binding protein fragile $\mathrm{X}$ mental retardation protein (FMRP) $[4,5]$. FMRP regulates the translation of mRNAs for proteins necessary for synaptic function and myelin integrity [6]. Most notably, the loss of FMRP leads to elevated levels of protein synthesis in the brain [7], impaired regulation of neuronal signaling and synaptic plasticity [8-12], and elevated levels of immature dendritic spines in the cortex and hippocampus [13-17]. These alterations may contribute to symptoms associated with FXS $[2,18]$. A preclinical model of FXS, the Fmr1 knockout (KO) mouse [19] is commonly used to study FXS and models many of the clinical manifestations of FXS.

Much of the research in FXS focuses on neuronal changes and neurodevelopmental symptoms [10, 20]. However, it has been reported that astrocyte and oligodendrocyte dysfunction may contribute to alterations in brain function associated with the Fmr1 KO mouse phenotype [21-23]. Astrocytes from Fmr1 KO mouse brain co-cultured with neurons from normal wild-type (WT) mouse brain caused Fmr1 KO-like neuronal morphology including increased axonal branching and immature dendritic spine density in WT neurons, suggesting astrocytes may contribute to the neuronal phenotype $[21,24$, 25]. FMRP binds to mRNAs of myelin proteins including myelin basic protein (MBP) [6, 23], 2',3'-cyclic-nucleotide $3^{\prime}$-phosphodiesterase (CNP), proteolipid protein, and myelin-associated glycoprotein [6]. Although the role of FMRP in oligodendrocyte maturation is still unknown, the finding that pre- and immature oligodendrocytes contain FMRP and levels are greatly reduced in mature oligodendrocytes suggests a developmental role for FMRP $[23,26]$. MBP is an abundant protein that ensures the stability of myelin sheaths [27]. Evidence of delayed myelination has been reported in the cerebellar white matter of postnatal Fmr1 KO mice, including reduced myelin thickness and reduced concentrations of MBP and CNP at postnatal day (PND) 7, all of which were normalized at PND 30 compared to WT mice [22]. Altered MBP levels at different postnatal ages suggest that the loss

Fig. 1. White matter volume between Fmr1 KO and WT mouse brains. The representative $\mathrm{T}_{2}$ images and ROI overlay are shown in a. The ROIs show representative white matter regions from WT PND 30 mouse brain, with corpus callosum (red), external capsule (green), internal capsule (yellow), cerebral peduncle (purple), and fimbria (blue). Regional white matter volume $\left(\mathrm{mm}^{3}\right.$; mean \pm standard error) in the developing WT (gray dashed line) and Fmr1 KO of FMRP regulation of MBP mRNA may have long-term consequences with respect to myelin integrity in $\mathrm{Fmrl}$ KO mouse brain [22].

Imaging studies of Fmr1 KO mouse brain revealed differences in regional brain volume, including an increase in hippocampal [28] and a decrease in cerebellar [22] volumes, as well as changes in brain metabolite concentrations that may influence myelination [28, 29]. In children with FXS, greater overall white matter volume and alterations of regional white matter volumes during brain development have been reported [30, 31]. Taken together, these studies provide evidence that alterations in white matter development may contribute to altered neurodevelopment associated with FXS. However, very little has been done to characterize the underlying alterations associated with changes in brain volume using advanced imaging techniques in FXS patients and Fmrl $\mathrm{KO}$ mouse brain.

In this study, we hypothesized decreased myelin levels are found in white matter during brain postnatal development in Fmr1 KO mice compared to the WT mice. Measurements were taken at critical time points in the course of myelination and neural network development, with PND 18 being before, and PND 21 during the peak of myelination and synaptogenesis in rodents [32]. Additionally, ages that coincide with previous reports of neural network development at PND 30 and maturation at PND 60 were also studied [32]. Using magnetization transfer and $\mathrm{T}_{2}$ imaging, we assessed microstructural white matter development in the corpus callosum, external capsule, internal capsule, cerebral peduncle, and hippocampal fimbria ex vivo in perfused brains from Fmr1 KO and WT mice. Histological staining was used to quantify myelin and verify results from $\mathrm{T}_{2}$ relaxation time and magnetization transfer imaging.

\section{Methods and Materials}

Animal Procedure

Fmr1 KO mice (JAX B6.129P2-fmr $1^{\text {tmICgr }}$ mice; Jackson Laboratory, Bar Harbor, ME, USA) from a C57Bl6J background were bred in the animal facility at the University of Maryland, Balti- (black solid line) mouse brains are shown in the corpus callosum (b), external (c) and internal capsule (d), cerebral peduncle (e), and fimbria (f). The ages studied were PND 18 (Fmr1 KO $n=9$, WT $n=9), 21(F m r 1 \mathrm{KO} n=12$, WT $n=14), 30(F m r 1 \mathrm{KO} n=13$, WT $n=12)$, and $60(F m r 1 \mathrm{KO} n=6$, WT $n=6)$. Interaction of genotype $\times$ age was not significant in white matter regions and the whole brain with respect to volume.

(For figure see next page.)
Altered Myelination during Brain

Development in Fmr1 KO Mice
Dev Neurosci 2019;41:274-289

DOI: $10.1159 / 000506679$ 

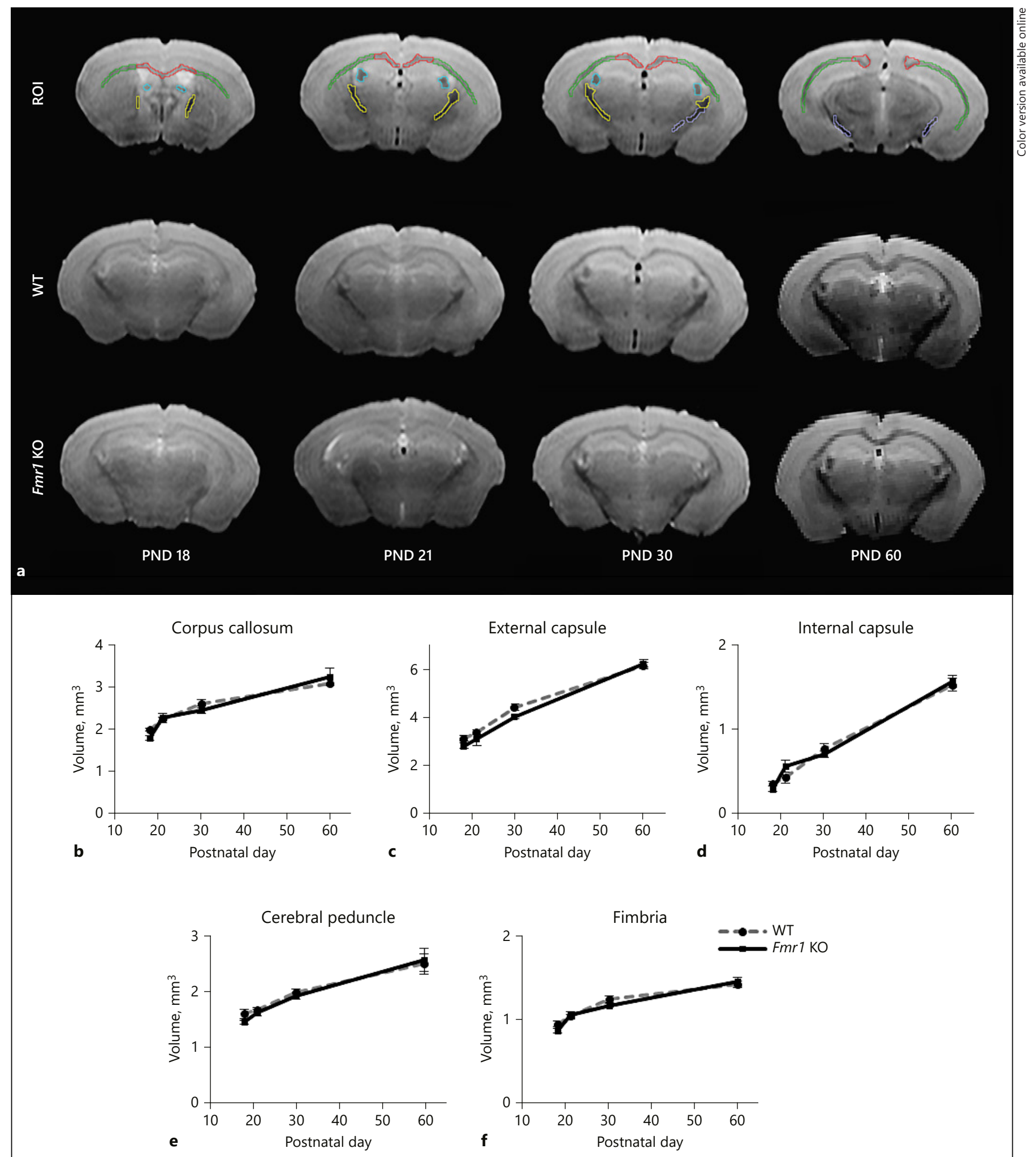
Table 1. Effects and interactions from 2-way analysis of variance

\begin{tabular}{|c|c|c|c|c|c|}
\hline & Region & df & Mean square & $F$ value & $p$ value \\
\hline \multicolumn{6}{|l|}{ Volume } \\
\hline \multirow[t]{5}{*}{ Genotype } & Corpus callosum & 1 & 0.027 & 0.315 & 0.577 \\
\hline & External capsule & 1 & 0.238 & 1.535 & 0.220 \\
\hline & Internal capsule & 1 & 0.001 & 0.048 & 0.827 \\
\hline & Cerebral peduncle & 1 & 0.002 & 0.038 & 0.846 \\
\hline & Fimbria & 1 & 0.003 & 0.266 & 0.608 \\
\hline \multirow[t]{5}{*}{ Age } & Corpus callosum & 3 & 4.063 & 46.699 & $<0.001$ \\
\hline & External capsule & 3 & 29.407 & 189.351 & $<0.001$ \\
\hline & Internal capsule & 3 & 4.168 & 203.613 & $<0.001$ \\
\hline & Cerebral peduncle & 3 & 2.903 & 50.557 & $<0.001$ \\
\hline & Fimbria & 3 & 0.770 & 77.064 & $<0.001$ \\
\hline \multirow[t]{5}{*}{ Genotype $\times$ age } & Corpus callosum & 3 & 0.095 & 1.095 & 0.357 \\
\hline & External capsule & 3 & 0.217 & 1.394 & 0.252 \\
\hline & Internal capsule & 3 & 0.028 & 1.369 & 0.260 \\
\hline & Cerebral peduncle & 3 & 0.016 & 0.273 & 0.845 \\
\hline & Fimbria & 3 & 0.009 & 0.884 & 0.453 \\
\hline \multicolumn{6}{|l|}{$T_{2}$ relaxation } \\
\hline \multirow[t]{5}{*}{ Genotype } & Corpus callosum & 1 & 35.060 & 2.091 & 0.153 \\
\hline & External capsule & 1 & 35.425 & 3.050 & 0.085 \\
\hline & Internal capsule & 1 & 4.814 & 0.594 & 0.443 \\
\hline & Cerebral peduncle & 1 & 7.209 & 0.927 & 0.339 \\
\hline & Fimbria & 1 & 7.209 & 1.393 & 0.242 \\
\hline \multirow[t]{5}{*}{ Age } & Corpus callosum & 3 & 145.239 & 8.662 & $<0.001$ \\
\hline & External capsule & 3 & 71.845 & 6.186 & $<0.001$ \\
\hline & Internal capsule & 3 & 20.849 & 2.573 & 0.061 \\
\hline & Cerebral peduncle & 3 & 16.209 & 2.084 & 0.110 \\
\hline & Fimbria & 3 & 79.850 & 6.036 & $<0.001$ \\
\hline \multirow{5}{*}{ Genotype $\times$ age } & Corpus callosum & 3 & 22.424 & 1.337 & 0.269 \\
\hline & External capsule & 3 & 17.468 & 1.504 & 0.221 \\
\hline & Internal capsule & 3 & 5.553 & 0.685 & 0.564 \\
\hline & Cerebral peduncle & 3 & 12.900 & 1.659 & 0.184 \\
\hline & Fimbria & 3 & 24.530 & 1.854 & 0.145 \\
\hline \multicolumn{6}{|c|}{ Magnetization transfer ratio } \\
\hline \multirow[t]{6}{*}{ Genotype } & Corpus callosum & 1 & 32.768 & 6.722 & 0.011 \\
\hline & External capsule & 1 & 37.016 & 8.406 & $<0.001$ \\
\hline & Internal capsule & 1 & 35.329 & 9.365 & $<0.001$ \\
\hline & Cerebral peduncle & 1 & 31.867 & 7.511 & 0.008 \\
\hline & Fimbria & 1 & 21.342 & 6.722 & 0.011 \\
\hline & Cerebellar white matter & 1 & 50.883 & 12.007 & 0.001 \\
\hline \multirow[t]{6}{*}{ Age } & Corpus callosum & 3 & 60.358 & 12.382 & $<0.001$ \\
\hline & External capsule & 3 & 49.900 & 11.332 & $<0.001$ \\
\hline & Internal capsule & 3 & 87.207 & 23.117 & $<0.001$ \\
\hline & Cerebral peduncle & 3 & 101.941 & 24.028 & $<0.001$ \\
\hline & Fimbria & 3 & 60.691 & 19.115 & $<0.001$ \\
\hline & Cerebellar white matter & 3 & 73.379 & 17.315 & $<0.001$ \\
\hline \multirow[t]{6}{*}{ Genotype $\times$ age } & Corpus callosum & 3 & 32.020 & 6.568 & $<0.001$ \\
\hline & External capsule & 3 & 28.590 & 6.492 & $<0.001$ \\
\hline & Internal capsule & 3 & 26.824 & 7.111 & $<0.001$ \\
\hline & Cerebral peduncle & 3 & 19.366 & 4.565 & 0.005 \\
\hline & Fimbria & 3 & 20.373 & 6.417 & $<0.001$ \\
\hline & Cerebellar white matter & 3 & 12.343 & 2.913 & 0.040 \\
\hline
\end{tabular}


Table 1 (continued)

\begin{tabular}{|c|c|c|c|c|c|}
\hline & Region & $\mathrm{df}$ & Mean square & $F$ value & $p$ value \\
\hline \multicolumn{6}{|l|}{ Black Gold II staining } \\
\hline \multirow[t]{5}{*}{ Genotype } & Corpus callosum & 1 & 0.00005 & 1.730 & 0.191 \\
\hline & External capsule & 1 & 0.00043 & 28.056 & $<0.001$ \\
\hline & Internal capsule & 1 & 0.00023 & 5.313 & 0.023 \\
\hline & Cerebral peduncle & 1 & 0.00003 & 0.959 & 0.329 \\
\hline & Fimbria & 1 & 0.00020 & 6.748 & 0.010 \\
\hline \multirow[t]{5}{*}{ Age } & Corpus callosum & 3 & 0.00056 & 18.787 & $<0.001$ \\
\hline & External capsule & 3 & 0.00197 & 129.770 & $<0.001$ \\
\hline & Internal capsule & 3 & 0.00351 & 80.925 & $<0.001$ \\
\hline & Cerebral peduncle & 3 & 0.00191 & 60.244 & $<0.001$ \\
\hline & Fimbria & 3 & 0.00046 & 15.299 & $<0.001$ \\
\hline \multirow[t]{5}{*}{ Genotype $\times$ age } & Corpus callosum & 3 & 0.00004 & 1.469 & 0.226 \\
\hline & External capsule & 3 & 0.00019 & 12.287 & $<0.001$ \\
\hline & Internal capsule & 3 & 0.00017 & 3.960 & 0.010 \\
\hline & Cerebral peduncle & 3 & 0.00009 & 2.993 & 0.033 \\
\hline & Fimbria & 3 & 0.00011 & 3.665 & 0.014 \\
\hline
\end{tabular}

Summary of two-way ANOVA for whole brain and regional white matter volumes, MTR, $T_{2}$ relaxation, and myelin density by ROIs. Included in the table are the $F$ value and $p$ value for genotype, age, and genotype $\times$ age interaction. Statistically significant effects $(p$ value $<0.05$ ) are indicated in bold. A post hoc was performed if there was a significant genotype $\times$ age interaction.

more. The Fmr1 KO mice were generated by mating homozygous Fmr1 KO female to hemizygous Fmr1 KO males. The WT mice were generated by homozygous mating of the WT female to the WT male. The Fmr1 KO mice were backcrossed for more than 10 generations. The Institutional Animal Care and Use Committee at the University of Maryland, Baltimore approved the protocol used in this study. All mice were weaned at PND 21. Food and water were given ad libitum.

Mice were studied at PND 18 (9 Fmr1 KO, 9 WT), PND 21 (12 Fmr1 KO, $14 \mathrm{WT}$ ), PND 30 (13 Fmr1 KO, $12 \mathrm{WT})$, and PND 60 (6 Fmr1 KO, 6 WT). Once animals reached the appropriate age, the male Fmr $1 \mathrm{KO}$ and WT mice were anesthetized with $4 \%$ isoflurane and perfused through the left ventricle with phosphate buffered saline (PBS), followed by $4 \%$ paraformaldehyde fixative. The whole brain was removed from the skull to ensure the brain was completely fixed before imaging and immersed in fixative for $48 \mathrm{~h}$. It was decided to excise the brain from the skull to ensure fixation of white matter structure and extra precaution was made to prevent damage to the forebrain and midbrain during dissection. The fixed brain was then immersed in PBS for 1 week to minimize the effect of the fixative on $\mathrm{T}_{2}$ relaxation time and magnetization transfer ratio (MTR) $[33,34]$. The fixation procedure was tightly controlled to minimize any variations associated with tissue processing. These fixed brains were used in order to detect subtle changes between white matter of Fmrl KO and WT mice using MRI. The fixed brains were placed in a customized conical tube filled with a proton-free susceptibility-matching fluid Fluorinert (3M, St. Paul, MN, USA) prior to MR imaging. Fluorinert does not degrade the sample because it is biologically inert [35] and has been safely used for in vivo molecular imaging [36].

\section{Magnetic Resonance Imaging}

MRI techniques used in this study are commonly used to characterize developmental and pathological changes in white matter because they are sensitive to the chemical and physical environments of water protons [37-40]. All experiments were performed on a Bruker Biospec 7.0 Tesla $30 \mathrm{~cm}$ horizontal bore scanner (Bruker Biospin MRI, Ettlingen, Germany) using Paravision 5.1 software. A Bruker 72-mm linear-volume coil as the transmitter and a four-channel Bruker ${ }^{1} \mathrm{H}$ surface array coil as the receiver were used for imaging. Prior to imaging, magnetic field inhomogeneity was adjusted using the FASTMAP technique [41]. Anatomical images were obtained using a 3D TurboRARE sequence covering a slab of $15 \mathrm{~mm}$ in thickness over the whole brain, from the forebrain to the hindbrain, to obtain $\mathrm{T}_{2}$-weighted images at a spatial resolution of $113 \times 150 \times 170 \mu \mathrm{m}$, using an echo time $(\mathrm{TE})$ and repeat time (TR) of $11 \mathrm{~ms}$ and 2,500 ms, respectively, with two averages.

Transverse relaxation time $T_{2}$ values decrease with the extent of myelination in white matter [42]. Quantitative information on $\mathrm{T}_{2}$ relaxation time was obtained using an eight echo, multi-echo spin echo sequence with three continuous slices centered on the hippocampus at Bregma -1.82 , without any gap. The spatial resolution was $200 \times 200 \mu \mathrm{m}$, acquired with $1 \mathrm{~mm}$ slice thickness, TEs of $9.3,27.9,46.5,65.1,83.7,102.3,120.9$, and $139.5 \mathrm{~ms}$ at a TR of $10,000 \mathrm{~ms}$, and two averages.

Changes in the relative levels of macromolecules can be detected using magnetization transfer, a technique that exploits the exchange between the bound protons in the macromolecules and the protons in free water, providing a contrast that is reflective of the concentration of macromolecules present in tissue [43-46]. In white matter, such a contrast would be indicative of myelin water content since myelin macromolecules such as lipids and proteins serve as the major pool of bound protons. Thus, magnetization transfer imaging provides an index of relative content of macromolecules in white matter and is reported as MTR [38, 45, 46].

The magnetization transfer images were obtained using a fast low shot (FLASH) $\mathrm{T}_{1}$ technique. Acquisition parameters were slice 
Table 2. Whole brain and normalized white matter volumes in Fmr1 KO and WT mice

\begin{tabular}{|c|c|c|c|c|}
\hline \multirow[t]{2}{*}{ Whole brain volume } & \multicolumn{4}{|l|}{ 2-way ANOVA } \\
\hline & $\mathrm{df}$ & Mean square & $F$ value & $p$ value \\
\hline Genotype & 1 & 0.421 & 0.701 & 0.405 \\
\hline Age & 3 & 143.306 & 238.515 & $<0.0001$ \\
\hline \multirow[t]{3}{*}{ Genotype $\times$ age } & 3 & 1.118 & 1.861 & 0.144 \\
\hline & \multicolumn{4}{|l|}{ Means } \\
\hline & WT volume, $\mathrm{mm}^{3}$ & SE & Fmr1 KO volume, $\mathrm{mm}^{3}$ & SE \\
\hline \multicolumn{5}{|l|}{ Age } \\
\hline PND 18 & 352.09 & 22.64 & 341.82 & 5.94 \\
\hline PND 21 & 342.47 & 9.58 & 376.16 & 14.71 \\
\hline PND 30 & 360.60 & 5.13 & 302.66 & 37.65 \\
\hline PND 60 & 387.02 & 4.72 & 412.60 & 15.97 \\
\hline \multirow{2}{*}{$\begin{array}{l}\text { Normalized white matter } \\
\text { volume }\end{array}$} & \multicolumn{4}{|l|}{ 2-way ANOVA } \\
\hline & $\mathrm{df}$ & Mean square & $F$ value & $p$ value \\
\hline \multicolumn{5}{|l|}{ Corpus callosum } \\
\hline Genotype & 1 & 0.000001 & 0.002 & $<0.0001$ \\
\hline Age & 3 & 0.01280 & 21.69 & 0.9634 \\
\hline Genotype $\times$ age & 3 & 0.00004 & 0.072 & 0.9749 \\
\hline \multicolumn{5}{|l|}{ External capsule } \\
\hline Genotype & 1 & 0.00014 & 0.1191 & 0.7310 \\
\hline Age & 3 & 0.00107 & 0.9054 & 0.1130 \\
\hline Genotype $\times$ age & 3 & 0.00024 & 0.2049 & 0.8926 \\
\hline \multicolumn{5}{|l|}{ Internal capsule } \\
\hline Genotype & 1 & 0.00006 & 0.2948 & 0.5889 \\
\hline Age & 3 & 0.01075 & 53.49 & $<0.0001$ \\
\hline Genotype $\times$ age & 3 & 0.00020 & 0.9854 & 0.4048 \\
\hline \multicolumn{5}{|l|}{ Cerebral peduncle } \\
\hline Genotype & 1 & 0.00001 & 0.0275 & 0.8687 \\
\hline Age & 3 & 0.00003 & 0.0843 & 0.9684 \\
\hline Genotype $\times$ age & 3 & 0.00011 & 0.3016 & 0.8241 \\
\hline \multicolumn{5}{|l|}{ Fimbria } \\
\hline Genotype & 1 & 0.000003 & 0.0315 & 0.8597 \\
\hline Age & 3 & 0.00035 & 3.810 & 0.0137 \\
\hline Genotype $\times$ age & 3 & 0.00002 & 0.2360 & 0.8710 \\
\hline
\end{tabular}

thickness $0.5 \mathrm{~mm}, 0.5 \mathrm{~mm}$ gap, 16 slices that covered the cerebral cortex and the cerebellum, spatial resolution of $200 \times 200 \mu \mathrm{m}$ over a field of view of $1.5 \times 1.5 \mathrm{~cm}, \mathrm{TE} / \mathrm{TR}=3.6 / 280 \mathrm{~ms}$, and 32 averages. For the magnetization transfer images $\left(\mathrm{M}_{\mathrm{s}}\right)$, a Gaussian offresonance saturation pulse was used with duration of $12.6 \mathrm{~ms}$ and flip angle of 180 degrees at an off-resonance frequency of $5,000 \mathrm{~Hz}$ from the center frequency of water protons. The reference magnetization transfer image $\left(\mathrm{M}_{0}\right)$ was scanned using the same parameters except without the off-resonance pulse.

\section{Image Processing}

Images were transferred offline to an independent database for further processing. Medical Image Processing, Analysis and Visualization tool (MIPAV v5.3.1, CIT; NIH, Bethesda, MD, USA) was used to obtain volumes of different regions and to extract information for computing the MTR. Regions of interest (ROIs) were drawn manually on both the $3 \mathrm{D} \mathrm{T}_{2}$ anatomical and magnetization transfer images by comparison with an anatomical reference atlas [47]. The image contrast was not clear enough for automatic segmentation at early ages; therefore, the ROIs were drawn by one operator for consistency. ROIs included the whole brain, corpus callosum, external capsule, internal capsule, cerebral peduncle, and fimbria. Both absolute and normalized white matter volume was obtained by dividing each regional white matter volume by whole brain volume. MTR was calculated as $\left(\left[\mathrm{M}_{0}-\mathrm{M}_{\mathrm{s}}\right] / \mathrm{M}_{0}\right) \times 100$, where $\mathrm{M}_{0}$ is the signal intensity from images obtained without the off-resonance pulse and $\mathrm{M}_{\mathrm{s}}$ is the signal intensity from images where the saturation pulse was applied [45]. $\mathrm{T}_{2}$ relaxation time was 
Table 2 (continued)

\begin{tabular}{|c|c|c|c|c|}
\hline & \multicolumn{4}{|l|}{ Means } \\
\hline & $\begin{array}{l}\text { WT normalized } \\
\text { volume }\end{array}$ & SE & $\begin{array}{l}\text { Fmr1 KO normalized } \\
\text { volume }\end{array}$ & SE \\
\hline \multicolumn{5}{|l|}{ Age and region } \\
\hline \multicolumn{5}{|l|}{ PND 18} \\
\hline Corpus callosum & 0.294 & 0.002 & 0.290 & 0.014 \\
\hline External capsule & 0.444 & 0.005 & 0.452 & 0.028 \\
\hline Internal capsule & 0.050 & 0.003 & 0.047 & 0.006 \\
\hline Cerebral peduncle & 0.137 & 0.006 & 0.135 & 0.006 \\
\hline Fimbria & 0.076 & 0.003 & 0.072 & 0.004 \\
\hline \multicolumn{5}{|l|}{ PND 21} \\
\hline Corpus callosum & 0.291 & 0.005 & 0.288 & 0.007 \\
\hline External capsule & 0.435 & 0.007 & 0.430 & 0.007 \\
\hline Internal capsule & 0.055 & 0.003 & 0.066 & 0.004 \\
\hline Cerebral peduncle & 0.138 & 0.005 & 0.135 & 0.006 \\
\hline Fimbria & 0.082 & 0.002 & 0.082 & 0.004 \\
\hline \multicolumn{5}{|l|}{ PND 30} \\
\hline Corpus callosum & 0.264 & 0.010 & 0.266 & 0.007 \\
\hline External capsule & 0.443 & 0.010 & 0.435 & 0.006 \\
\hline Internal capsule & 0.076 & 0.005 & 0.076 & 0.004 \\
\hline Cerebral peduncle & 0.135 & 0.003 & 0.142 & 0.004 \\
\hline Fimbria & 0.081 & 0.003 & 0.082 & 0.002 \\
\hline \multicolumn{5}{|l|}{ PND 60} \\
\hline Corpus callosum & 0.227 & 0.001 & 0.230 & 0.008 \\
\hline External capsule & 0.450 & 0.007 & 0.444 & 0.010 \\
\hline Internal capsule & 0.112 & 0.007 & 0.112 & 0.005 \\
\hline Cerebral peduncle & 0.138 & 0.012 & 0.139 & 0.013 \\
\hline Fimbria & 0.074 & 0.002 & 0.075 & 0.003 \\
\hline
\end{tabular}

Normalized volume was calculated by dividing regional white matter volume $\left(\mathrm{mm}^{3}\right)$ by its respective whole brain volume $\left(\mathrm{mm}^{3}\right)$. The mean normalized volume and standard error for each white matter region in the Fmr1 $\mathrm{KO}$ and WT mouse brain are presented at PND 18, 21, 30, and 60. Also included is a summary of two-way ANOVA for whole brain volume and normalized white matter volume. The normalized volume was calculated by dividing the regional white matter volume by the whole brain volume for each mouse. The $F$ value and $p$ value for genotype, age, and interaction of genotype $\times$ age are presented.

measured using an in-house Matlab program [48]. The data from all TEs for each ROI were fitted to a mono-exponential decay curve. The first echo at $9.3 \mathrm{~ms}$ was ignored to minimize potential contamination from the stimulated echo. The volumes, $\mathrm{T}_{2}$ relaxation times, and MTR values from each ROI were obtained and analyzed for statistically significant differences.

\section{Histology}

Following MRI, six of the perfused brains from each genotype and age were placed in 30\% sucrose solution for cryoprotection. Brains were then frozen and coronal sections of $40 \mu \mathrm{m}$ in thickness were prepared with a cryostat at $-20^{\circ} \mathrm{C}$. One section was collected from every 12 sections, approximately $0.50 \mathrm{~mm}$ apart. Sections were stained for myelin with Black Gold II (EMD Millipore, Billerica, MA, USA) by the following procedure described by Schmued et al. [49]. Mounted slides were rehydrated with two washes of de-ionized water, followed by staining with $0.3 \%$ Black Gold II in saline solution at $60^{\circ} \mathrm{C}$. After staining was complete, the slides were washed in $1 \%$ sodium thiosulfate solution at $60^{\circ} \mathrm{C}$ followed by three washes in water at room temperature [49]. Images were taken on a brightfield Olympus BX53 microscope at 10x magnification and analyzed using Bioquant Life Sciences 2013 v13.5.6 software (Bioquant Image Analysis Inc., Nashville, TN, USA). A white field correction was applied to all images prior to obtaining optical density. The red channel was used to determine density because Black Gold II stains myelinated fibers red-brown. The intensity of myelin staining in white matter regions was measured as optical density. The optical density was calculated as the log of the intensity of the ROI divided by the intensity of the background [50]. The optical density value was normalized to the area (in $\mu \mathrm{m}^{2}$ ) of the ROI. Optical densities were measured between Bregma 0.50 to $-2.46 \mathrm{~mm}$, which included $5-6$ sections of the corpus callosum and external capsule, 1-2 sections with the internal capsule, $2-3$ sections for cerebral peduncle, and 3-4 sections for the fimbria. The ROIs selected for histology were matched with anatomical references by Franklin and Paxinos [47] during ROI selection and number of ROIs were adjusted to with age to cover similar white matter regions through- 

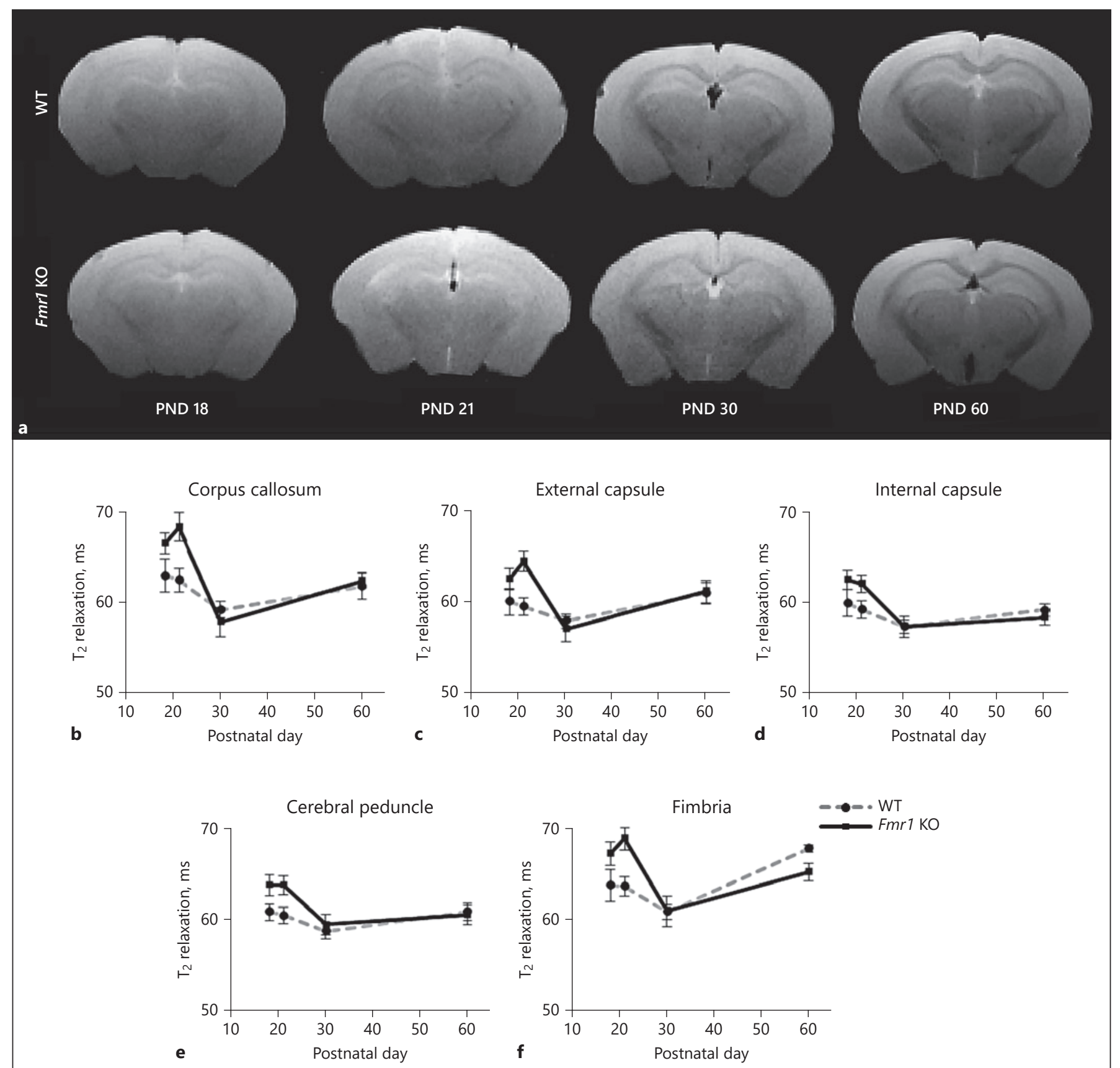

Fig. 2. $\mathrm{T}_{2}$ relaxation time in white matter regions of the Fmr1 KO and WT mouse brain. The representative images at $\mathrm{TE}=9.3$ are shown for Fmr1 KO and WT mouse brains at each age in a. $\mathrm{T}_{2}$ relaxation time ( $\mathrm{ms} \pm$ standard error) changes in WT (gray dashed line) and Fmr1 KO (black solid line) mice from PND 18 (Fmr1 KO $n=9$, WT $n=9), 21($ Fmrl KO $n=12$, WT $n=14), 30($ Fmrl KO $n=12$, WT $n=12)$, and $60(F m r 1 \mathrm{KO} n=6$, WT $n=6)$. Relaxation times were measured in white matter regions of the corpus callosum (b), external (c) and internal capsule (d), cerebral peduncle (e), and fimbria (f). No significant genotype $\times$ age interaction was found in $\mathrm{T}_{2}$ relaxation. 
out the forebrain and midbrain. While the number of brains used for histology was less than the number of brains imaged, each brain was randomly selected among the litter group to avoid litter effect and bias.

\section{Statistical Analysis}

All statistical analyses were performed in SPSS (IBM Corp., 2013, IBM SPSS Statistics for Windows, Version 22.0, Armonk, NY, USA). A separate two-way analysis of variance (ANOVA) was performed for each region in each parameter, including volume, normalized volume, MTR, $\mathrm{T}_{2}$ relaxation, and optical density. Each two-way ANOVA compared the effect of genotype, age, and the interaction of genotype $\times$ age. Genotype and age effects were analyzed by Student's $t$ tests if the interaction between factors was statistically significant $(p<0.05)$. To control for multiple pairwise comparisons, a false discovery rate with threshold of alpha $=0.05$ was performed on the $p$ values. The threshold assumes $5 \%$ of significant $p$ values may be false positives, and if a significant $p$ value does not pass false discovery rate then that $p$ value may be a false positive.

\section{Results}

\section{White Matter Volumes}

Representative images of the fixed brain are shown in Figure 1a for each age and genotype. Additionally, Figure la shows a representative image of the drawn white matter ROIs from WT PND 30 mouse brain. No differences in regional white matter or whole brain volumes were found between Fmr1 KO and WT mice (Fig. 1; Table 1). The white matter volume normalized to whole brain volume was also not significantly different between Fmrl $\mathrm{KO}$ and WT mice (Table 2). Significant effect of age was observed in all white matter regions studied and the white matter volume increased with age (Fig. 1; Table 1). The genotype $\times$ age interaction was not statistically significant in the whole brain and regional white matter volumes (Table 1), as well as with normalized regional white matter volumes (Table 2), indicating that the developmental courses of change in white matter volumes were similar between the two genotypes.

\section{$\mathrm{T}_{2}$ Relaxation Time}

$\mathrm{T}_{2}$ relaxation time can provide insights into white matter environment and generally decreases following development of white matter [42]. Representative $\mathrm{T}_{2}$ images at $\mathrm{TE}=9.3 \mathrm{~ms}$ are shown in Figure 2a for each age and genotype. $\mathrm{T}_{2}$ relaxation time was measured in the corpus callosum, external capsule, internal capsule, cerebral peduncle, and fimbria of brains from Fmr1 $\mathrm{KO}$ and WT mice (Fig. $2 b-f$, respectively). The genotype $\times$ age interaction was not statistically significant in the white matter regions studied (Table 1) indicating that changes in $\mathrm{T}_{2}$ relaxation time over the course of development were not different between the two genotypes. The significant effect of age in the corpus callosum, external capsule, and fimbria is indicative of developmental decrease in $T_{2}$ relaxation times [42] (Table 1). These trends in white matter regions of WT mice showed decreased $\mathrm{T}_{2}$ relaxation times between PND 18 and PND 30 as expected over the course of myelination. In Fmr1 KO mice, however, $\mathrm{T}_{2}$ relaxation time decreased more sharply in the corpus callosum, external capsule, and fimbria between PND 21 and PND 30, suggesting delayed patterns in myelination. It should be noted that poor signal to noise prevented analysis of one Fmr1 KO mouse brain at PND 30.

\section{Magnetization Transfer Ratio}

MTR is considered to be an index of macromolecular content in white matter, including myelin proteins and lipids that contribute to the structural integrity of white matter [38]. MTR detected differences in macromolecular content, indicative of differences in white matter maturation of Fmr1 KO mouse brain compared to WT brain (Fig. 3). Figure 3a shows representative images at the center frequency of water protons for Fmr1 KO and WT mouse brains at PNDs 18, 21, 30, and 60. Significant genotype $\times$ age interaction was found in MTR data for all white matter regions studied (Table 1). In WT mice, MTR tended to be fairly level between PND 18 and PND 30 and increased thereafter (Fig. 3). At PND 60, when the brain networks are more mature [32], MTR in all regions examined was higher in WT compared to Fmr1 KO mice (Fig. 3). Before the peak of myelination at PND 18, MTR in the white matter regions of Fmr $1 \mathrm{KO}$ mice was lower in the internal capsule $(t[2.56], p<0.05)$, cerebral peduncle ( $t[2.41], p<0.05)$, fimbria $(t[2.42], p<0.05)$, and cerebellar white matter $(t[2.58], p<0.05)$ (Fig. $3 \mathrm{~d}, \mathrm{e}, \mathrm{f}$, and g, respectively) compared to WT mice. MTR in Fmr1 KO mouse brain showed a steep increase between PND 18 and PND 30 followed by a decrease or leveling off between PND 30 and PND 60 (Fig. 3). No differences were found at PND 21. At PND 30, during a period when the neural networks begin to establish along with continued myelination in the mouse brain [32], the internal capsule $(t[2.21], p<0.05)$ and fimbria $(t[2.33], p<0.05)$ showed significantly higher MTR in Fmr1 KO mouse brains compared to the WT (Fig. 3d, f, respectively). At PND 60, when the brain networks are more mature [32], lower MTR was observed in the corpus callosum ( $t$ [2.29], $p<$ $0.05)$, external capsule ( $t$ [2.54], $p<0.05)$, and internal capsule $(t$ [2.27], $p<0.05)$ in Fmr1 KO mouse brains 


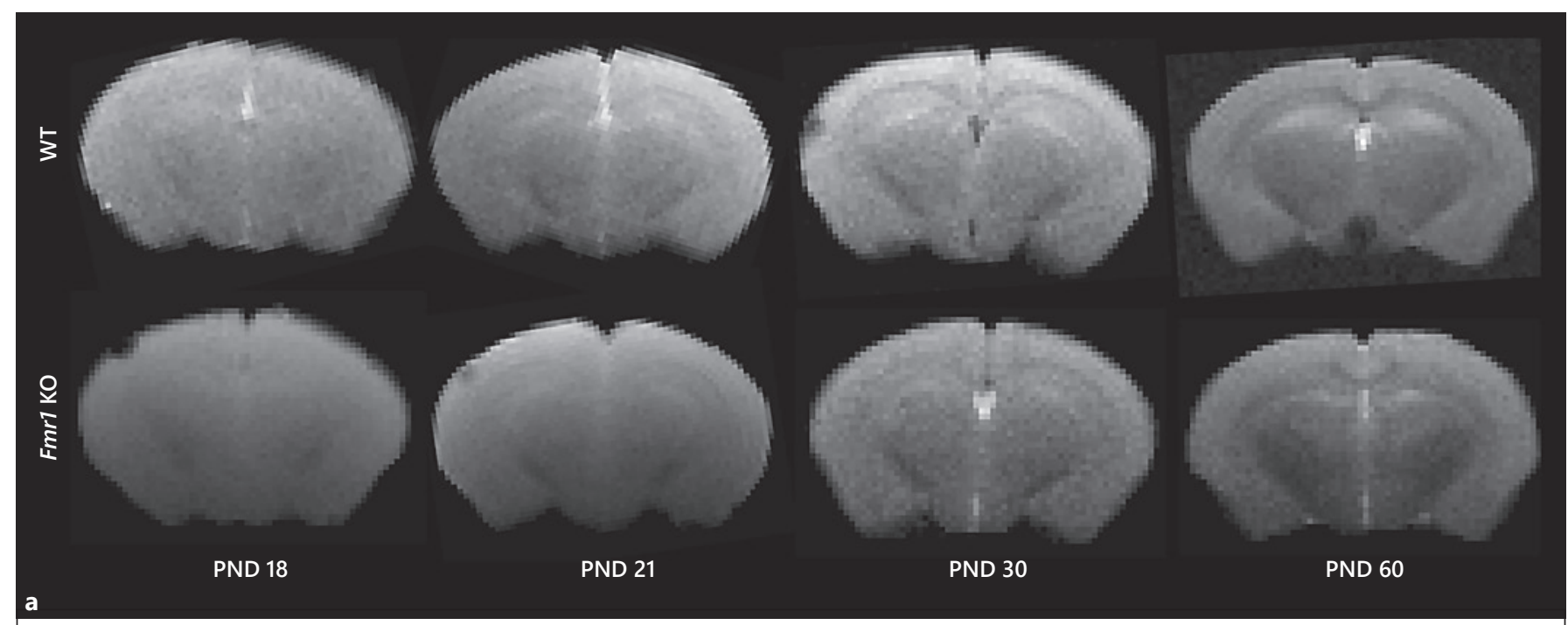

Corpus callosum
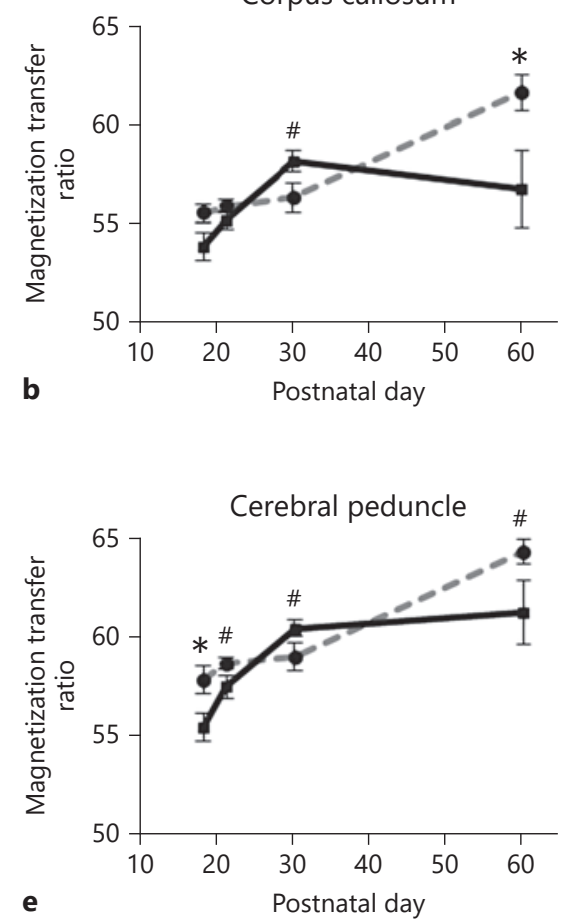

External capsule

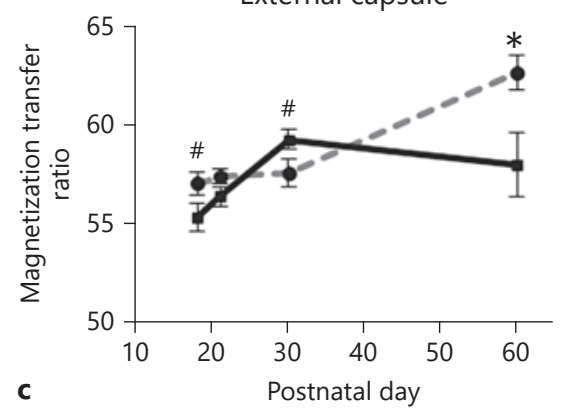

Fimbria

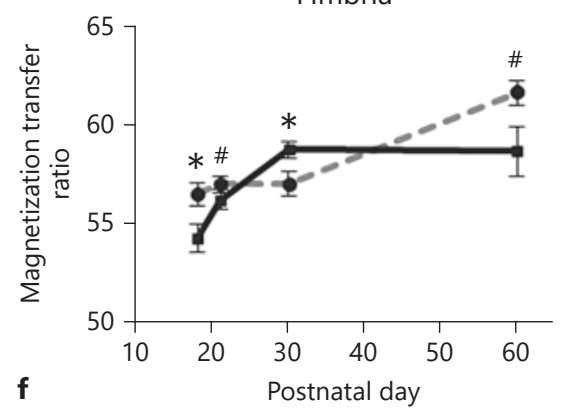

Internal capsule

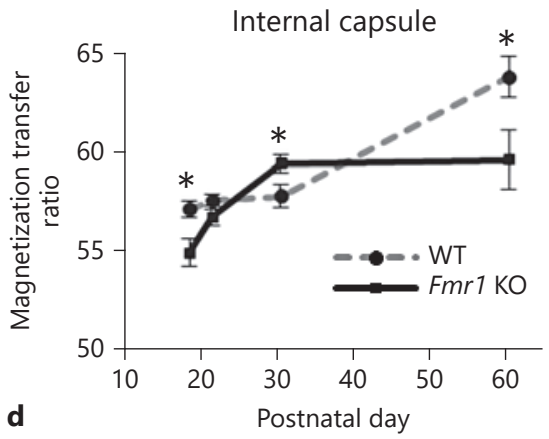

Fig. 3. Magnetization transfer ratio of white matter regions between Fmr1 KO and WT mouse brains. The representative images at the center frequency of water protons are shown in a for Fmr1 $\mathrm{KO}$ and WT mouse brains. Magnetization transfer ratio (mean \pm standard error) from regional white matter between WT (gray dashed line) and Fmr1 KO mice (black solid line) in the corpus callosum (b), external (c) and internal capsule (d), cerebral pe- duncle (e), fimbria (f), and cerebellar white matter (g) at PND 18 $(F m r 1 \mathrm{KO} n=9$, WT $n=9), 21(F m r 1 \mathrm{KO} n=12$, WT $n=14), 30$ $(F m r 1 \mathrm{KO} n=13$, WT $n=12)$, and $60(F m r 1 \mathrm{KO} n=6$, WT $n=6)$. A significant genotype $\times$ age interaction was found in all white matter regions. The significant genotype differences in MTR between WT and Fmr1 KO mice are marked with $* p<0.05$ and ${ }^{\#} p<0.10$. 


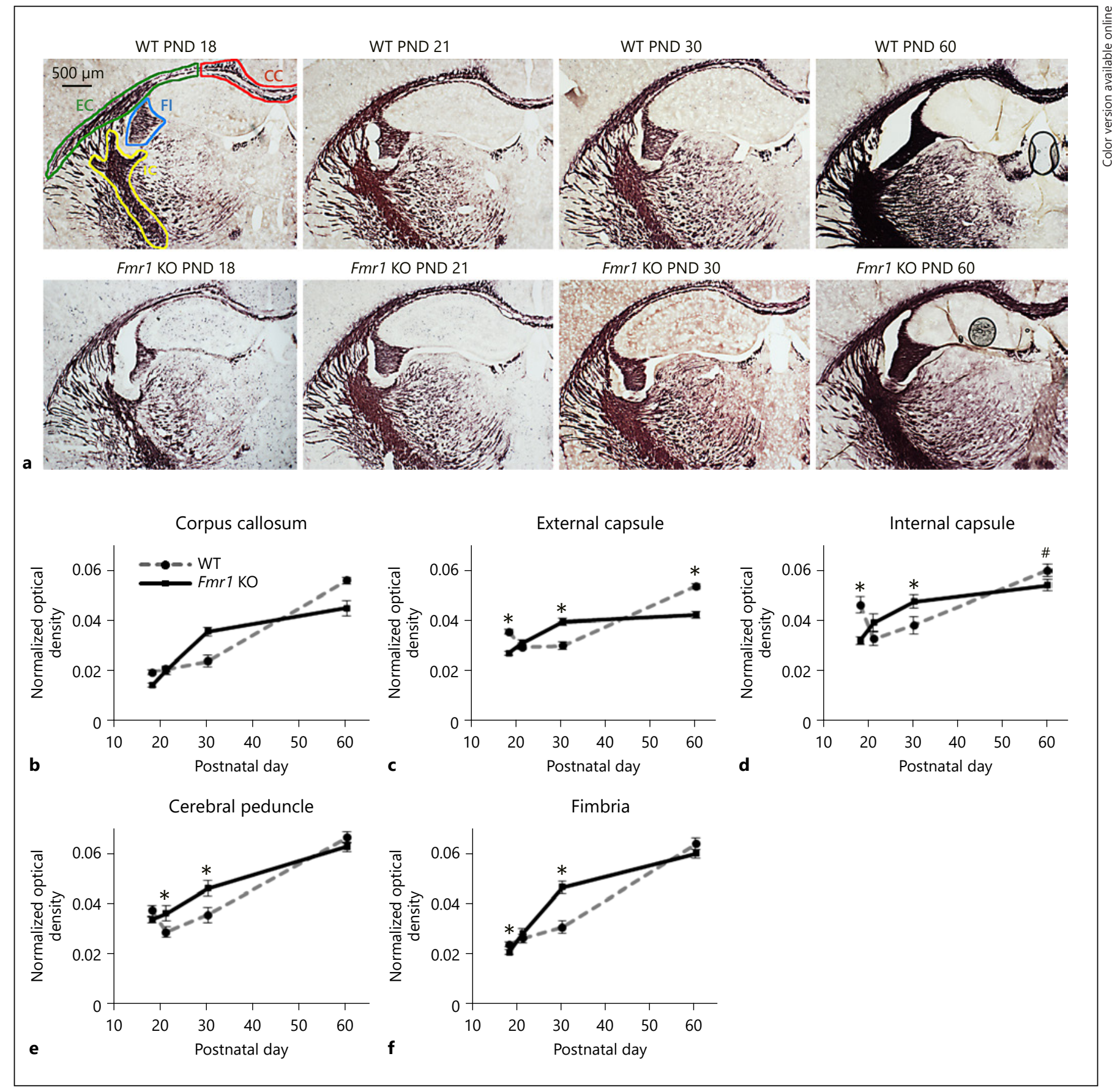

Fig. 4. Myelin density of Fmr1 KO and WT mouse brains. a Representative images of myelin staining with Black Gold II in WT and Fmr1 KO mouse brains. Approximate ROIs are drawn with corpus callosum (CC) in red, external capsule (EC) in green, internal capsule (IC) in yellow, and fimbria (FI) in blue. The cerebral peduncle is not shown but is posterior to the internal capsule. The images were taken between Bregma -1.70 and -2.30 at PND 18 (Fmr1 KO $n=6$, WT $n=6), 21($ Fmr1 KO $n=6$, WT $n=6), 30($ Fmr1 KO $n=6$, WT $n=6)$, and $60($ Fmr1 KO $n=6$, WT $n=6)$. The scale bar represents $500 \mu \mathrm{m}$ and is shown in the top left figure. Myelin density was measured by optical density normalized to the area of the ROI. Normalized optical density (mean \pm standard error) changes are shown for each ROI including corpus callosum (b), external capsule (c), internal capsule (d), cerebral peduncle (e), and fimbria (f) for both genotypes. Significant differences between Fmr1 KO and WT myelin density are indicated with ${ }^{*} p<0.05$ and ${ }^{*} p<0.10$. 
compared to the WT (Fig. 3b-d, respectively). The significant $p$ values from multiple pairwise comparisons passed false discovery rate with a threshold of alpha $=$ 0.05 . The developmental differences in MTR between Fmr1 KO and WT mouse brains suggested a lower content of myelin proteins and/or lipids at PND 18 and 60 in the white matter of Fmr1 KO mouse brain. Overall, alterations in MTR are suggestive of fluctuation in macromolecule content during development in the Fmr1 KO mouse brain that may have an impact on stable myelin structure formation.

\section{Myelin Staining}

To directly determine myelin content in brain, we stained tissue with Black Gold II, a histological stain for myelin [49]. Figure 4a shows the myelin staining of a representative section from Fmr1 KO mouse brain and WT mouse brain at each age. Myelin density measured from Black Gold II staining showed significant interaction of genotype $\times$ age in the external capsule, internal capsule, cerebral peduncle, and fimbria (Table 1). The myelin density was lower in Fmr1 KO mouse brain at PND 18 in the external capsule $(t[6.88], p<0.001)$, internal capsule $(t[3.50], p<0.001)$, and fimbria $(t[2.01], p<0.05)$ compared to the corresponding regions of WT mouse brain (Fig. 4c, d, and f, respectively). Myelin density at PND 21 was elevated in the cerebral peduncle of Fmr1 KO mouse brain compared to WT $(t[2.10], p<0.05)$ (Fig. 4e). By PND 30, the myelin density was elevated in many white matter regions of the Fmr1 KO mouse brain, including the external capsule $(t[4.82], p<0.001)$, internal capsule $(t[2.11], p<0.05)$, and fimbria $(t[4.61], p<0.001)$ when compared to the corresponding regions of WT mouse brain (Fig. 4c, d, and f, respectively). At PND 60, the myelin density in Fmr1 KO mouse brain was lower in the external capsule $(t[6.61], p<0.001)$ compared to the WT brain (Fig. 4c). The significant $p$ values passed false discovery rate (alpha $=0.05)$ for multiple pairwise comparisons.

The myelin density in the white matter regions of Fmr1 KO mice showed different developmental time courses than the WT mice (Fig. 4). In WT brain, myelin density increased steeply between PND 30 and PND 60 in the corpus callosum and external capsule, whereas in the corresponding regions of Fmr 1 KO brain, the increase in myelin density occurred between PND 18 and PND 30 and tended to level off thereafter. The myelin densities of internal capsule, cerebral peduncle, and hippocampal fimbria in WT brain increased steadily from PND 18 to 60, whereas in Fmr1 KO brain, the myelin density in-

Altered Myelination during Brain

Development in Fmr1 KO Mice creased more gradually from PND 18 to 60 . The myelin density in the external and internal capsules showed similar trends as the MTR results, where Fmr1 KO mouse showed lowered myelin density at PND 18 followed by elevated levels at PND 30, which was reduced at PND 60 compared to the corresponding regions of WT mouse brain (Fig. 4).

\section{Discussion}

\section{Myelination Delay in White Matter in the Developing} Fmr1 KO Mouse

Myelination of axons in normally developing human brains starts prenatally and undergoes conspicuous growth during the first 2 years of life [51], then continues to increase at a lower rate from childhood into early adulthood, and declines in late adulthood $[52,53]$. In comparison, the peak of myelination in the normally developing rodent brain occurs between PND 20 and 21 [32], grows steadily at a reduced rate throughout adulthood, and declines at around 18 months of age $[32,52,53]$. Moreover, the developmental process of myelination varies regionally [54].

Our results demonstrate an abnormal pattern of accumulation of macromolecules determined by MTR and myelin staining during early postnatal development in brains of Fmr 1 KO mice compared to brains of WT mice (Fig. 3, 4). The results of MTR and the myelin density measurements show similar trends in the Fmr1 KO mouse brain, suggesting that histological changes in myelin density correspond closely with MTR in the fixed brain. In the present study, the differences in myelin density and MTR at PND 18, 30, and 60 in the Fmrl KO mice compared to WT suggests that alterations in forebrain and midbrain white matter, most notably in the external and internal capsules, occur throughout postnatal brain development including before the peak of myelination at PND 18 and during development and maturation of the neural networks at PND 30 and PND 60, respectively.

Reduced myelin thickness has been reported in the cerebellar white matter of Fmr1 KO mice at PND 7, although differences were not observed at PND 15 or older ages [22]. However, reduced rates of myelination or delayed myelination may also be present at older ages, which could explain lowered MTR and myelin density at PND 18 and PND 60 found in white matter regions of the current study. Magnetization transfer imaging is sensitive to the macromolecules in white matter, particularly the proteins and lipids in myelin [55]. Previous in-depth research 
demonstrated that cholesterol and myelin lipids contribute significantly to the magnetization transfer effect [55, 56]. The MTR from the present study suggests altered levels of white matter macromolecules, including lipids and proteins, at different stages of brain development that could contribute to altered myelin composition in Fmr 1 $\mathrm{KO}$ mice. When placed in context with myelin staining, the most prominent differences were alterations during the developmental phase of the internal capsule and later in the external capsule in the maturing Fmrl KO mice brains. The alteration in myelin composition and density during brain development suggests that the process of myelination is dysregulated during development in Fmrl KO brain, which could adversely influence neuronal function and potentially have a negative impact on the formation and maturation of brain networks. Future studies in the mouse model will incorporate in vivo functional imaging methods in Fmr1 KO mice at the critical developmental ages revealed from the current studies.

Reduced MTR has been associated with pathological states of demyelination and axonal degeneration in patients with and in preclinical models of multiple sclerosis $[37,39,40]$. In an animal model of multiple sclerosis, lower MTR was found in the corpus callosum and external capsule of mice treated with cuprizone, an agent that caused demyelination [39]. It is important to note that similar MTR values were found for in vivo and ex vivo imaging of the mouse model of multiple sclerosis by Thiessen et al. [39].

A previous study with the MBP-deficient Shiverer mouse revealed no differences in Black Gold II staining compared to controls, suggesting that Black Gold II staining of myelin may have greater specificity to lipids [57]. Therefore, altered MTR and myelin staining in Fmr1 KO mouse brain likely reflects differences in lipid content because myelin composition is composed of $70-85 \%$ lipids [54]. Thus, the similar trends between MTR and myelin density data from the present study suggest alterations in lipid levels in the developing Fmr1 KO mouse brain, in addition to altered myelin protein levels reported by Pacey et al. [22]. A recent study reported reduced plasma cholesterol and reduced low- and high-density lipoproteins in male FXS patients (4-20+ years) compared to the normal control population [58]. Although it has not been determined whether brain cholesterol levels might be altered in FXS patients or Fmrl $\mathrm{KO}$ mice, cholesterol is known to be heavily incorporated into myelin particularly during the peak of myelination in the normal brain [59] and the cholesterol utilized for myelination is mainly synthesized in the brain [60]. Furthermore, an overall cholesterol deficiency could contribute to impaired neurotransmission and has been associated with neurodegenerative diseases [61]. Thus, the lowered MTR and myelin density found in white matter of Fmrl KO mice may be due to decreased lipids and also the lack of FMRP regulation on the mRNA levels and synthesis of myelin proteins [6], which may lead to delayed myelination as observed in the present study.

\section{White Matter Volume in the FXS Brain}

Numerous MRI studies have reported alterations in brain volumes of young and adolescent FXS patients, including changes in regional gray and white matter volumes of cortical and subcortical regions, compared to normally developing children $[30,31,62,63]$. Although the current findings do not show consistent differences in white matter volume between Fmr1 KO and WT mouse brains, our data agree with a recent study that reported no difference in white matter volumes of the corpus callosum, internal capsule, and fimbria in fixed C57Bl6J Fmr1 KO mouse brain compared to WT at PND 60 [64]. An earlier in vivo study from our group found increased volume of the hippocampus in Fmr1 KO brains compared to WT brains [28]. The C57Bl6J strain of Fmr1 KO mouse was chosen for this study because it is a widely used model of FXS $[15,16,65]$ and a previous study demonstrating delayed myelination also used this model [22]. Although white matter volumes were not changed, the magnetization transfer imaging technique used in this study showed evidence of alterations in myelin and white matter in developing Fmr1 KO mice.

\section{Imaging the Fixed Brain}

The imaging findings along with results from myelin staining suggest that magnetization transfer imaging may be particularly useful to better understand the microstructure of white matter in FXS brain in vivo. However, the current findings have to be taken in context of the limitations of the study. It is likely that the $\mathrm{T}_{2}$ and MTR values measured in vivo may be different from those measured in a fixed tissue sample because the fixative solution has been shown to affect the $\mathrm{T}_{2}$ and MTR values compared to in vivo measurements $[33,34]$. In the present study precautions were taken to minimize the effect of fixative in $\mathrm{T}_{2}$ relaxation and MTR in the fixed brain, based on published studies of fixed and in vivo brain samples $[33,34]$. In addition, it has been shown that the data trends from fixed samples are similar to in vivo with $\mathrm{T}_{2}$ [34] and with MTR following immersion of PFA fixed brain tissue in PBS [39]. 
Our goal in this study was to obtain an accurate assessment of any subtle changes in white matter development by obtaining high-resolution volumetric, $\mathrm{T}_{2}$, and MTR data. Thus, we elected to perform these measurements on fixed brains to stabilize brain structure, allow longer imaging durations, and eliminate confounds of any motion artifacts as in previous studies $[22,29,64]$. The findings of the current study regarding the utility of MTR in revealing developmental changes in Fmr1 KO mouse are compelling. Future studies should focus on using MTR in conjunction with other advanced MRI techniques in vivo to assess their utility as imaging markers for FXS and also to assess whether such changes alter brain connectivity in Fmr1 KO mouse.

\section{Conclusions}

In this study, we found altered levels of myelin and macromolecules in the white matter of Fmr1 KO mouse brain at key developmental ages compared to the corresponding regions of WT mouse brain. We observed delayed myelination before the peak of myelination at PND 18, and then increased myelin density at PND 30 suggesting compensation for the delayed myelination, followed by lowered myelin levels in adult Fmr1 KO mouse brain compared to WT mouse brain. Differences in white matter and myelin between Fmr1 KO and WT mouse brains were found at several ages during development and could potentially contribute to changes in the brain networks of Fmrl $\mathrm{KO}$ mouse. Alterations in white matter and myelin that coincided with key stages of brain development including early myelination, the peak of myelination and synaptogenesis, neural network development, and maturation in mouse brain suggest dysregulation of myelination and white matter maturation in Fmr $1 \mathrm{KO}$ mouse brain during development and suggest complex differences in white matter development which may ultimately result in altered brain function.

\section{Acknowledgements}

The authors thank Dr. Jaylyn Waddell, Dr. Shiyu Tang, and Dr. Carolyn B. Smith for their advice and assistance with statistics. Thank also to the Core for Translational Imaging @ Maryland (CTRIM), which is part of the University of Maryland School of Medicine Center for Innovative Biomedical Resources in Baltimore for providing the imaging services.

\section{Statement of Ethics}

The Institutional Animal Care and Use Committee at the University of Maryland, Baltimore approved the protocol used in this study.

\section{Disclosure Statement}

The authors have no conflicts of interests to disclose.

\section{Funding Sources}

This study was supported by the FRAXA Research Foundation, and NIH P01 grant HD016596 (M.C.M.).

\section{Author Contributions}

D.S. performed histological and MRI experiments, data analysis, and writing of manuscript. S.X. contributed technical and conceptual expertise to MRI and assisted in writing and proofreading of manuscript. J.Z. contributed technical and analytical expertise to MRI and assisted in proofreading of manuscript. M.C.M. contributed to design of the experiments, histological expertise, and preparation of manuscript. R.P.G. contributed to design of the experiments, MRI expertise, and preparation of manuscript.

\section{References}

1 Coffee B, Keith K, Albizua I, Malone T, Mowrey J, Sherman SL, et al. Incidence of fragile $\mathrm{X}$ syndrome by newborn screening for methylated FMR1 DNA. Am J Hum Genet. 2009 Oct; 85(4):503-14.

2 Garber KB, Visootsak J, Warren ST. Fragile X syndrome. Eur J Hum Genet. 2008 Jun;16(6): 666-72.
3 Verkerk AJ, Pieretti M, Sutcliffe JS, Fu YH, Kuhl DP, Pizzuti A, et al. Identification of a gene (FMR-1) containing a CGG repeat coincident with a breakpoint cluster region exhibiting length variation in fragile $\mathrm{X}$ syndrome. Cell. 1991 May;65(5):905-14.

4 Ashley CT Jr, Wilkinson KD, Reines D, Warren ST. FMR1 protein: conserved RNP family domains and selective RNA binding. Science. 1993 Oct;262(5133):563-6.
5 Devys D, Lutz Y, Rouyer N, Bellocq JP, Mandel JL. The FMR-1 protein is cytoplasmic, most abundant in neurons and appears nor$\mathrm{mal}$ in carriers of a fragile $\mathrm{X}$ premutation. Nat Genet. 1993 Aug;4(4):335-40.

6 Darnell JC, Van Driesche SJ, Zhang C, Hung KY, Mele A, Fraser CE, et al. FMRP stalls ribosomal translocation on mRNAs linked to synaptic function and autism. Cell. $2011 \mathrm{Jul}$; 146(2):247-61. 
7 Qin M, Kang J, Burlin TV, Jiang C, Smith CB. Postadolescent changes in regional cerebral protein synthesis: an in vivo study in the FMR1 null mouse. J Neurosci. 2005 May; 25(20):5087-95.

8 Paluszkiewicz SM, Martin BS, Huntsman MM. Fragile X syndrome: the GABAergic system and circuit dysfunction. Dev Neurosci. 2011;33(5):349-64.

9 Gross C, Berry-Kravis EM, Bassell GJ. Therapeutic strategies in fragile $\mathrm{X}$ syndrome: dysregulated $\mathrm{mGluR}$ signaling and beyond. Neuropsychopharmacology. 2012 Jan;37(1):17895.

10 Hagerman R, Lauterborn J, Au J, Berry-Kravis $\mathrm{E}$. Fragile $\mathrm{X}$ syndrome and targeted treatment trials. Results Probl Cell Differ. 2012;54: 297-335.

11 Martin BS, Huntsman MM. Pathological plasticity in fragile X syndrome. Neural Plast. 2012;2012:275630.

12 Cea-Del Rio CA, Huntsman MM. The contribution of inhibitory interneurons to circuit dysfunction in Fragile X Syndrome. Front Cell Neurosci. 2014 Aug;8:245.

13 Irwin SA, Galvez R, Greenough WT. Dendritic spine structural anomalies in fragile- $\mathrm{X}$ mental retardation syndrome. Cereb Cortex. 2000 Oct;10(10):1038-44.

14 Irwin SA, Idupulapati M, Gilbert ME, Harris JB, Chakravarti AB, Rogers EJ, et al. Dendritic spine and dendritic field characteristics of layer $\mathrm{V}$ pyramidal neurons in the visual cortex of fragile-X knockout mice. Am J Med Genet. 2002 Aug;111(2):140-6.

15 Bilousova TV, Dansie L, Ngo M, Aye J, Charles JR, Ethell DW, et al. Minocycline promotes dendritic spine maturation and improves behavioural performance in the fragile X mouse model. J Med Genet. 2009 Feb;46(2): 94-102.

16 Grossman AW, Aldridge GM, Lee KJ, Zeman MK, Jun CS, Azam HS, et al. Developmental characteristics of dendritic spines in the dentate gyrus of Fmr1 knockout mice. Brain Res. 2010 Oct; 1355:221-7.

17 Pan F, Aldridge GM, Greenough WT, Gan WB. Dendritic spine instability and insensitivity to modulation by sensory experience in a mouse model of fragile $\mathrm{X}$ syndrome. Proc Natl Acad Sci USA. 2010 Oct;107(41):1776873.

18 Kidd SA, Lachiewicz A, Barbouth D, Blitz RK, Delahunty C, McBrien D, et al. Fragile X syndrome: a review of associated medical problems. Pediatrics. 2014 Nov;134(5):995-1005.

19 Bakker C; The Dutch-Belgian Fragile X Consortium. Fmr1 knockout mice: a model to study fragile X mental retardation. Cell. 1994 Jul;78(1):23-33

20 Berry-Kravis E, Sumis A, Hervey C, Mathur S. Clinic-based retrospective analysis of psychopharmacology for behavior in fragile $\mathrm{x}$ syndrome. Int J Pediatr. 2012;2012:843016.

21 Jacobs S, Doering LC. Astrocytes prevent abnormal neuronal development in the fragile $\mathrm{x}$ mouse. J Neurosci. 2010 Mar;30(12):4508-14.
22 Pacey LK, Xuan IC, Guan S, Sussman D, Henkelman RM, Chen Y, et al. Delayed myelination in a mouse model of fragile $\mathrm{X}$ syndrome. Hum Mol Genet. 2013 Oct;22(19):3920-30.

23 Wang H, Ku L, Osterhout DJ, Li W, Ahmadian A, Liang Z, et al. Developmentally-programmed FMRP expression in oligodendrocytes: a potential role of FMRP in regulating translation in oligodendroglia progenitors. Hum Mol Genet. 2004 Jan;13(1):79-89.

24 Jacobs S, Cheng C, Doering LC. Hippocampal neuronal subtypes develop abnormal dendritic arbors in the presence of Fragile $\mathrm{X}$ astrocytes. Neuroscience. 2016 Jun;324:202-17.

25 Jacobs S, Nathwani M, Doering LC. Fragile X astrocytes induce developmental delays in dendrite maturation and synaptic protein expression. BMC Neurosci. 2010 Oct;11(1):132.

26 Gholizadeh S, Halder SK, Hampson DR. Expression of fragile $\mathrm{X}$ mental retardation protein in neurons and glia of the developing and adult mouse brain. Brain Res. 2015 Jan;1596: 22-30.

27 Harauz G, Ladizhansky V, Boggs JM. Structural polymorphism and multifunctionality of myelin basic protein. Biochemistry. 2009 Sep;48(34):8094-104.

28 Shi D, Xu S, Waddell J, Scafidi S, Roys S, Gullapalli RP, et al. Longitudinal in vivo developmental changes of metabolites in the hippocampus of Fmr1 knockout mice. J Neurochem. 2012 Dec;123(6):971-81.

29 Ellegood J, Pacey LK, Hampson DR, Lerch JP, Henkelman RM. Anatomical phenotyping in a mouse model of fragile $\mathrm{X}$ syndrome with magnetic resonance imaging. Neuroimage. 2010 Nov;53(3):1023-9.

30 Hazlett HC, Poe MD, Lightbody AA, Styner M, MacFall JR, Reiss AL, et al. Trajectories of early brain volume development in fragile $\mathrm{X}$ syndrome and autism. J Am Acad Child Adolesc Psychiatry. 2012 Sep;51(9):921-33.

31 Hoeft F, Carter JC, Lightbody AA, Cody Hazlett H, Piven J, Reiss AL. Region-specific alterations in brain development in one- to three-year-old boys with fragile $\mathrm{X}$ syndrome. Proc Natl Acad Sci USA. 2010 May;107(20): 9335-9.

32 Semple BD, Blomgren K, Gimlin K, Ferriero DM, Noble-Haeusslein LJ. Brain development in rodents and humans: identifying benchmarks of maturation and vulnerability to injury across species. Prog Neurobiol. 2013 Jul-Aug;106-107:1-16.

33 Schmierer K, Wheeler-Kingshott CA, Tozer DJ, Boulby PA, Parkes HG, Yousry TA, et al. Quantitative magnetic resonance of postmortem multiple sclerosis brain before and after fixation. Magn Reson Med. 2008 Feb;59(2): 268-77.

34 Shepherd TM, Thelwall PE, Stanisz GJ, Blackband SJ. Aldehyde fixative solutions alter the water relaxation and diffusion properties of nervous tissue. Magn Reson Med. 2009 Jul; 62(1):26-34.
35 Flaim SF. Pharmacokinetics and side effects of perfluorocarbon-based blood substitutes. Artif Cells Blood Substit Immobil Biotechnol. 1994;22(4):1043-54.

36 Giraudeau C, Geffroy F, Mériaux S, Boumezbeur F, Robert P, Port M, et al. 19F molecular MR imaging for detection of brain tumor angiogenesis: in vivo validation using targeted PFOB nanoparticles. Angiogenesis. 2013 Jan; 16(1):171-9.

37 Schmierer K, Scaravilli F, Altmann DR, Barker GJ, Miller DH. Magnetization transfer ratio and myelin in postmortem multiple sclerosis brain. Ann Neurol. 2004 Sep;56(3):407-15.

38 Wozniak JR, Lim KO. Advances in white matter imaging: a review of in vivo magnetic resonance methodologies and their applicability to the study of development and aging. Neurosci Biobehav Rev. 2006;30(6):762-74.

39 Thiessen JD, Zhang Y, Zhang H, Wang L, Buist R, Del Bigio MR, et al. Quantitative MRI and ultrastructural examination of the cuprizone mouse model of demyelination. NMR Biomed. 2013 Nov;26(11):1562-81.

40 Bonnier G, Roche A, Romascano D, Simioni S, Meskaldji D, Rotzinger D, et al. Advanced MRI unravels the nature of tissue alterations in early multiple sclerosis. Ann Clin Transl Neurol. 2014 Jun;1(6):423-32.

41 Gruetter R. Automatic, localized in vivo adjustment of all first- and second-order shim coils. Magn Reson Med. 1993 Jun;29(6):80411.

42 Paus T, Collins DL, Evans AC, Leonard G, Pike B, Zijdenbos A. Maturation of white matter in the human brain: a review of magnetic resonance studies. Brain Res Bull. 2001 Feb;54(3):255-66.

43 Finelli DA. Magnetization transfer in neuroimaging. Magn Reson Imaging Clin N Am. $1998 \mathrm{Feb} ; 6(1): 31-52$.

44 Finelli DA, Hurst GC, Amantia P Jr, Gullapali RP, Apicella A. Cerebral white matter: technical development and clinical applications of effective magnetization transfer (MT) power concepts for high-power, thin-section, quantitative MT examinations. Radiology. 1996 Apr;199(1):219-26.

45 Henkelman RM, Stanisz GJ, Graham SJ. Magnetization transfer in MRI: a review. NMR Biomed. 2001 Apr;14(2):57-64.

46 Wolff SD, Balaban RS. Magnetization transfer contrast (MTC) and tissue water proton relaxation in vivo. Magn Reson Med. 1989 Apr; 10(1):135-44.

47 Franklin KBJ, Paxinos G. The Mouse Brain in Stereotaxic Coordinates. Academic Press; 2007.

48 Mullins RJ, Xu S, Pereira EF, Mamczarz J, Albuquerque EX, Gullapalli RP. Delayed hippocampal effects from a single exposure of prepubertal guinea pigs to sub-lethal dose of chlorpyrifos: a magnetic resonance imaging and spectroscopy study. Neurotoxicology. 2013 May;36:42-8. 
49 Schmued L, Bowyer J, Cozart M, Heard D, Binienda Z, Paule M. Introducing Black-Gold II, a highly soluble gold phosphate complex with several unique advantages for the histochemical localization of myelin. Brain Res. 2008 Sep;1229:210-7.

50 Kayser K, Liewald F, Kremer K, Tacke M. Integrated optical density (IOD), syntactic structure analysis, and survival in operated lung carcinoma patients. Pathol Res Pract. 1994 Nov; 190(11):1031-8.

51 Kinney HC, Brody BA, Kloman AS, Gilles FH. Sequence of central nervous system myelination in human infancy. II. Patterns of myelination in autopsied infants. J Neuropathol Exp Neurol. 1988 May;47(3):217-34.

52 Andersen SL. Trajectories of brain development: point of vulnerability or window of opportunity? Neurosci Biobehav Rev. 2003 JanMar;27(1-2):3-18.

53 Xie F, Zhang JC, Fu H, Chen J. Age-related decline of myelin proteins is highly correlated with activation of astrocytes and microglia in the rat CNS. Int J Mol Med. 2013 Nov;32(5): $1021-8$.
54 Quarles RH, Morell P. Myelin Formation, Structure and Biochemistry. Basic Neurochemistry: Molecular, Cellular and Medical Aspects. 8th ed. Academic Press, Inc.; 2012. p. 51.

55 Stanisz GJ, Kecojevic A, Bronskill MJ, Henkelman RM. Characterizing white matter with magnetization transfer and T(2). Magn Reson Med. 1999 Dec;42(6):1128-36.

56 Koenig SH. Cholesterol of myelin is the determinant of gray-white contrast in MRI of brain. Magn Reson Med. 1991 Aug;20(2): 285-91.

57 Savaskan NE, Weinmann O, Heimrich B, Eyupoglu IY. High resolution neurochemical gold staining method for myelin in peripheral and central nervous system at the light- and electron-microscopic level. Cell Tissue Res. 2009 Aug;337(2):213-21.

58 Berry-Kravis E, Levin R, Shah H, Mathur S, Darnell JC, Ouyang B. Cholesterol levels in fragile X syndrome. Am J Med Genet A. 2015 Feb;167A(2):379-84.

59 Saher G, Brügger B, Lappe-Siefke C, Möbius W, Tozawa R, Wehr MC, et al. High cholesterol level is essential for myelin membrane growth. Nat Neurosci. 2005 Apr;8(4):468-75.
60 Jurevics H, Morell P. Cholesterol for synthesis of myelin is made locally, not imported into brain. J Neurochem. 1995 Feb;64(2):895-901.

61 Zhang J, Liu Q. Cholesterol metabolism and homeostasis in the brain. Protein Cell. 2015 Apr;6(4):254-64.

62 Reiss AL, Lee J, Freund L. Neuroanatomy of fragile X syndrome: the temporal lobe. Neurology. $1994 \mathrm{Jul} ; 44(7): 1317-24$.

63 Gothelf D, Furfaro JA, Hoeft F, Eckert MA, Hall SS, O'Hara R, et al. Neuroanatomy of fragile $\mathrm{X}$ syndrome is associated with aberrant behavior and the fragile $\mathrm{X}$ mental retardation protein (FMRP). Ann Neurol. 2008 Jan;63(1): 40-51.

64 Lai JK, Lerch JP, Doering LC, Foster JA, Ellegood J. Regional brain volumes changes in adult male FMR1-KO mouse on the FVB strain. Neuroscience. 2016 Mar;318:12-21.

65 Haberl MG, Zerbi V, Veltien A, Ginger M, Heerschap A, Frick A. Structural-functional connectivity deficits of neocortical circuits in the Fmr1 (-/y) mouse model of autism. Sci Adv. 2015 Nov;1(10):e1500775. 